\title{
Novel progesterone receptors: neural localization and possible functions
}

\author{
Sandra L. Petersen ${ }^{1 *}$, Karlie A. Intlekofer ${ }^{2}$, Paula J. Moura-Conlon ${ }^{1}$, Daniel N. Brewer ${ }^{1}$, \\ Javier Del Pino Sans ${ }^{3}$ and Justin A. Lopez ${ }^{4}$ \\ 1 Molecular and Cellular Neuroendocrinology, Department of Veterinary and Animal Sciences, University of Massachusetts Amherst, Amherst, MA, USA \\ ${ }^{2}$ Department of Psychology, University of Vermont, Burlington, VT, USA \\ ${ }^{3}$ Toxicology and Pharmacology Department, Complutense University of Madrid, Madrid, Spain \\ ${ }^{4}$ Department of Physiology and Pharmacology, Center for Neuroscience, West Virginia University, Morgantown, WV, USA
}

\section{Edited by:}

John J. Peluso, University of

Connecticut Health Center, USA

\section{Reviewed by:}

Cynthia L Bethea, Oregon Health \& Science University, USA

Paul S. Cooke, University of Florida, USA

\section{*Correspondence:}

Sandra L. Petersen, Molecular and Cellular Neuroendocrinology,

Department of Veterinary and Animal Sciences, University of Massachusetts Amherst, $661 \mathrm{~N}$ Pleasant, Amherst, MA 01003, USA e-mail: spetersen@vasci.umass.edu
Progesterone $\left(\mathrm{P}_{4}\right)$ regulates a wide range of neural functions and likely acts through multiple receptors. Over the past 30 years, most studies investigating neural effects of $\mathrm{P}_{4}$ focused on genomic and non-genomic actions of the classical progestin receptor (PGR). More recently the focus has widened to include two groups of non-classical $P_{4}$ signaling molecules. Members of the Class II progestin and adipoQ receptor (PAQR) family are called membrane progestin receptors (mPRs) and include: $\mathrm{mPR} \alpha$ (PAQR7), mPR $\beta$ (PAQR8), mPR $\gamma$ (PAQR5), mPR (PAQR6), and mPRe (PAQR9). Members of the b5-like heme/steroid-binding protein family include progesterone receptor membrane component 1 (PGRMC1), PGRMC2, neudesin, and neuferricin. Results of our recent mapping studies show that members of the PGRMC1/S2R family, but not mPRs, are quite abundant in forebrain structures important for neuroendocrine regulation and other non-genomic effects of $\mathrm{P}_{4}$. Herein we describe the structures, neuroanatomical localization, and signaling mechanisms of these molecules. We also discuss possible roles for Pgrmc1/S2R in gonadotropin release, feminine sexual behaviors, fluid balance and neuroprotection, as well as catamenial epilepsy.

\section{Keywords: PGR, PGRMC1, 25DX, PAQR, MPR}

\section{INTRODUCTION}

It is now clear that actions of progesterone $\left(\mathrm{P}_{4}\right)$ in the nervous system go beyond its well-studied roles in regulating gonadotropinreleasing hormone $(\mathrm{GnRH})$ release and feminine sexual behaviors (Chabbert-Buffeta et al., 2000; Mani and Blaustein, 2012). $\mathrm{P}_{4}$ also modulates such diverse processes as neuroprotection and neuroplasticity (Nilsen and Brinton, 2003; Peterson et al., 2012; Baudry et al., 2013; Sanchez et al., 2013), mood (Watson et al., 2012), neurogenesis (Bali et al., 2012) and neuroinflammation (Giatti et al., 2012). Therefore, it is not surprising that, in addition to the classical progestin receptor $(\mathrm{PR}), \mathrm{P}_{4}$ exerts effects through multiple non-classical receptors.

Two groups of putative non-classical signaling molecules have emerged as likely mediators of $\mathrm{P}_{4}$ actions in the nervous system. One group consists of membrane $\mathrm{P}_{4}$ receptors (mPRs) that belong to the progestin and adipoQ receptor (PAQR) family. Five of these molecules, $\operatorname{mPR} \alpha, \operatorname{mPR} \beta, \operatorname{mPR} \gamma, \operatorname{mPR} \delta$, and $\operatorname{mPR} \varepsilon$, are found in the brain (Thomas and Pang, 2012; Pang et al., 2013). These receptors contain seven trans-membrane domains and are thought to be unique $\mathrm{G}$ protein-coupled receptors that act through cAMP (Thomas and Pang, 2012). Of these receptors, $\mathrm{mPR} \alpha, \mathrm{mPR} \beta$, and $\mathrm{mPR} \gamma$ decrease cellular accumulation of cAMP, while $\mathrm{mPR} \delta$ and $\mathrm{mPR} \varepsilon$ increase accumulation (Karteris et al., 2006; Pang et al., 2013). There is evidence that mPRs are not always found in the plasma membrane or coupled to $G$ proteins
(Ashley et al., 2006; Krietsch et al., 2006; Smith et al., 2008). Thus, it has been suggested that they may function as alkaline ceramidases, enzymes that deacylate ceramides to produce lipid second messengers (Villa et al., 2009; Moussatche and Lyons, 2012). However, there is yet little data from mammalian cells to support this idea.

Members of a second group of molecules are structurally similar in that each contains a highly conserved cytochrome b5-heme/steroid binding domain (Kimura et al., 2012). This group includes progesterone receptor membrane component 1 [PGRMC1; also known as known 25Dx (Selmin et al., 1996)], PGRMC2, neudesin and neuferricin (Kimura et al., 2012). Each of these molecules is found in neural tissue (Krebs et al., 2000; Kimura et al., 2005, 2006, 2010; Intlekofer and Petersen, 2011), but only PGRMC1 has been reported to bind $\mathrm{P}_{4}$ (Meyer et al., 1996; Peluso et al., 2008, 2009). Recently, it has been suggested that PGRMC1 is the same molecule as the sigma-2 receptor (Xu et al., 2011). If this hypothesis is verified, it will expand our knowledge of how PGRMC1 might function in the nervous system because the sigma- 2 receptor was primarily studied therein.

\section{LOCALIZATION OF $\mathrm{P}_{4}$ SIGNALING MOLECULES IN SPECIFIC NUCLEI OF THE BRAIN}

Although mPRs and PGRMC1-related molecules are found in the brain, most early studies did not compare the distributions 
of these molecules using techniques that provide detailed neuroanatomical information. Such information gives important clues to the functions regulated by the various receptors. Therefore, we used in situ hybridization (ISH) to map genes encoding PR, $m P R \alpha, m P R \beta$ and PGRMC1, as well as its binding partners PGRMC2 and SERPINE $1 \mathrm{mRNA}$ binding protein 1 (SERBP1), throughout the rat forebrain (Intlekofer and Petersen, 2011).

Somewhat surprisingly, neither $m P R \alpha$ nor $m P R \beta$ is expressed specifically in neuroendocrine or other nuclei that mediate $\mathrm{P}_{4}$ functions (Intlekofer and Petersen, 2011). Moreover, except for very high $\operatorname{mPR} \beta$ mRNA levels in the nucleus of the oculomotor cranial nerve, $m P R \alpha$ and $m P R \beta$ expression is generally homogeneous and relatively low throughout the forebrain. In contrast, mRNAs encoding PGRMC1, PGRMC2 and SERBP1 are found in discrete neuroendocrine nuclei and in hippocampal, cortical and cerebellar regions that control functions modulated by $\mathrm{P}_{4}$ (Intlekofer and Petersen, 2011). More recently, we mapped expression of $\operatorname{mPR} \delta$ and $\mathrm{mPR} \varepsilon$ mRNAs in the rat forebrain and found no specific signal for either of these mRNAs (MouraConlon and Petersen, unpublished data).

Neuferricin is a recently discovered extracellular heme-binding protein that facilitates neurogenesis in cultured progenitor cells (Kimura et al., 2010). In preliminary in situ hybridization studies, we failed to detect neuferricin mRNA in the rat forebrain. In contrast, the distribution pattern of neudesin gene expression is strikingly similar to that of $p r$ in the rat forebrain, particularly in regions containing the anteroventral periventricular, arcuate, and the ventromedial nuclei [compare Figure 1 and (Simerly et al., 1996; Shughrue et al., 1997)]. This 171-amino acid secreted protein is expressed in neural, but not glial cells (Kimura et al., 2005). Similarly, it promotes differentiation of neurons and inhibits differentiation of astrocytes (Kimura et al., 2006). Neudesin exerts these effects through protein kinase and phosphatidylinositol-3 kinase pathways (Kimura et al., 2006), and its cytochrome $b_{5}$-like
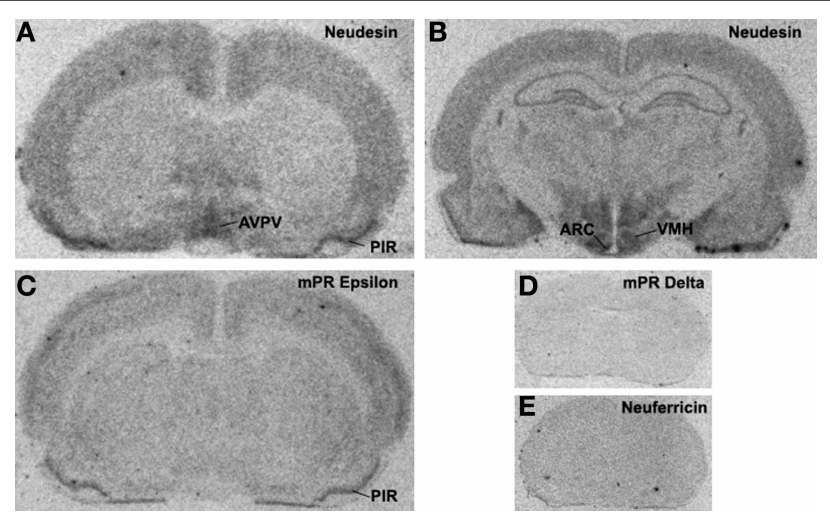

FIGURE 1 | X-ray film autoradiograms showing results of in situ hybridization studies. Twelve-micron coronal frozen sections were hybridized to ${ }^{33}$ P-dATP end-labeled antisense deoxynucleotide probes for neudesin (Panels $\mathbf{A}$ and $\mathbf{B}$ ), mPRe (Panel $\mathbf{C}$ ), mPR $\delta$ (Panel $\mathbf{D}$ ) or neuferricin (Panel E). Hybridization was as described previously (Intlekofer and

Petersen, 2011) and sections were placed against Kodak BioMax MR film (Rochester, NY) for 2 weeks. heme/steroid-binding domain is also required (Kimura et al., 2008). The role of neudesin in the regulation of adult neural functions is unclear, but the striking similarity of the neudesin and PR mRNA distribution patterns (Figure 1) suggests the possibility that neudesin may act in concert with PR to regulate neuroendocrine functions.

Our neuroanatomical findings indicate that pgrmcl is the most abundant putative membrane $\mathrm{P}_{4}$ receptor gene expressed in neuroendocrine regions; therefore, this review focuses on possible roles of PGRMC1 in regulating some of these functions. For a more detailed review of all the putative non-classical $\mathrm{P}_{4}$ signaling molecules, see (Petersen et al., 2013).

\section{STRUCTURES OF PGRMC1 AND PGRMC2}

PGRMC1 has been partially purified from liver membranes (Meyer et al., 1996), spontaneously immortalized rat granulosa cells (Peluso et al., 2008), and human granulosa/luteal cells (Peluso et al., 2009). Results of studies using these preparations suggests that $\mathrm{PGRMC1}$ binds $\mathrm{P}_{4}$ with high affinity [ $\mathrm{k}_{d}$ estimates of 10, 11, and $35 \mathrm{nM}$ (Meyer et al., 1996; Peluso et al., 2008, 2009)]. However, the idea that PGRMC1 alone binds $\mathrm{P}_{4}$ is not universally accepted (Rohe et al., 2009). For example, Min et al. found that GST-tagged rat inner zone antigen [found to be identical to PGRMC1; see (Cahill, 2007)] expressed in E. coli did not bind $\mathrm{P}_{4}$ in pull-down assays (Min et al., 2005).

It is possible that there are other $\mathrm{P}_{4}$-binding proteins in the partially purified preparations wherein binding has been detected (Meyer et al., 1996; Peluso et al., 2008, 2009), but studies in rat granulosa cells suggest that PGRMC1 accounts for the specific $\mathrm{P}_{4}$ binding. Peluso and colleagues showed that partially purified GFP-PGRMC1 fusion protein binds $\mathrm{P}_{4}$ with nM affinity and deletions in various parts of the PGRMC1 molecule reduce $\mathrm{P}_{4}$ binding (Peluso et al., 2008). SERBP1 (also called plasminogen activator inhibitor 1 RNA binding protein; PAIRBP1) is important for PGRMC1 functions (Peluso et al., 2013), but the $\mathrm{P}_{4}$ binding site on PGRMC1 and the site for SERBP1 interaction differ (Peluso et al., 2008). In addition, depletion of SERBP1 increases, rather than decreases, $\mathrm{P}_{4}$ binding in spontaneously immortalized granulosa cells (Peluso et al., 2013). Finally, perhaps the most compelling evidence that PGRMC1 binds $\mathrm{P}_{4}$ comes from work showing that knockdown of PGRMC1 by $60 \%$ reduces $\mathrm{P}_{4}$ binding by the same percentage (Peluso et al., 2008).

Few studies have examined binding of steroids other than $\mathrm{P}_{4}$ to PGRMC1. Early work characterizing PGRMC1showed that $\mathrm{P}_{4}$, but not dexamethasone, aldosterone or $\beta$-estradiol bind specifically to partially purified PGRMC1 in microsomal or solubilized membrane fractions from porcine liver (Meyer et al., 1996). In the same studies, it was found that corticosterone and testosterone bind with affinities $\sim 25 \%$ that of $\mathrm{P}_{4}$, and cortisol with a relative affinity of $4 \%$. Thus, PGRMC1 appears to preferentially bind $\mathrm{P}_{4}$.

PGRMC1 is relatively small [194 amino acids (Falkenstein et al., 1996)] with a molecular weight estimated between 25 and 28kDa (Meyer et al., 1996; Selmin et al., 1996; Raza et al., 2001; Peluso et al., 2009). However, higher molecular weight molecules can also be detected and likely represent dimers (Meyer et al., 1996), multimers (Losel et al., 2005), or molecules 
modified post-translationally through sumoylation or other processes (Peluso et al., 2012). PGRMC1 contains an N-terminal extracellular domain, a transmembrane domain, and a cytoplasmic region with a heme-binding domain (Peluso et al., 2006; Cahill, 2007).

Consistent with evidence that PGRMC1 and sigma-2 receptors are the same protein (Xu et al., 2011), the two molecules have similar steroid hormone-binding profiles with high affinity for $\mathrm{P}_{4}$ (Meyer et al., 1996; Peluso et al., 2008). Moreover, sigma-2 ligand binding colocalizes with PGRMC1 expression in the endoplasmic reticulum (ER) and mitochondria (Xu et al., 2011). In addition, changes in PGRMC1levels correlate with changes in sigma-2 ligand binding ( $\mathrm{Xu}$ et al., 2011). Finally, sigma-2 receptors regulate intracellular calcium levels (Vilner and Bowen, 2000) and apoptosis (Vilner and Bowen, 1993; Vilner et al., 1995), as does PGRMC1 (Viero et al., 2006; Peluso et al., 2008; Bashour and Wray, 2012; Lai et al., 2012).

PGRMC2 is structurally similar to PGRMC1 (Cahill, 2007; Wendler and Wehling, 2013), except in the N-terminus and transmembrane domain. This finding may explain why PGRMC2 does not bind $\mathrm{P}_{4}$ (Peluso, Pers. Commun.), because the $\mathrm{P}_{4}$ binding site of PGRMC1 is in the transmembrane domain [26]. In contrast, PGRMC1 and PGRMC2 both bind the same members of a group of heme-containing molecules, the cytochrome $\mathrm{P} 450$ proteins (Albrecht et al., 2012), suggesting that the heme-binding sites function similarly in PGRMC1 and PGRMC2. It is notable that PGRMC2 expression widely overlaps that of PGRMC1 in brain nuclei (Intlekofer and Petersen, 2011). However, the role of PGRMC2 in $\mathrm{P}_{4}$ signaling in the nervous system or in other tissues remains unclear.

\section{POSSIBLE ROLES FOR PGRMC1 IN REGULATING RAPID NEUROENDOCRINE RESPONSES GONADOTROPIN RELEASE}

Most studies examining PGRMC1 functions have focused on non-neural reproductive tissues such as the ovary (Kowalik and Kotwica, 2008; Peluso, 2011) and uterus (Zhang et al., 2008). Results of our neuroanatomical studies suggest that PGRMC1 and its partners also regulate the neural structures that control reproductive functions. The region in which mRNAs encoding PGRMC1, PGRMC2 and SERBP1 are highest is the anteroventral periventricular nucleus (AVPV), a group of cells in which $\mathrm{E}_{2}$ acts to induce luteinizing hormone (LH) surge release and ovulation in rodents (Petersen et al., 2003). E2 triggers the LH surge mechanism, at least in part, by upregulating PR expression in the AVPV (Chappell and Levine, 2000) and by increasing synthesis of neurosteroids in the region (Micevych and Sinchak, 2008, 2011). The surge is then rapidly amplified by rising levels of circulating $\mathrm{P}_{4}$ (Levine, 1997). Based on the high levels of expression in the AVPV, it is possible that PGRMC1 may mediate one or both of these rapid effects of $\mathrm{P}_{4}$. Unfortunately, this idea is difficult to test because the LH surge does not occur in the absence of PR (Chappell et al., 1997, 1999).

One possible way in which PGRMC1 might enhance LH surge release is by increasing neurosteroid synthesis in the AVPV. Local steroid production in the AVPV is important for the LH surge (Micevych and Sinchak, 2011) and PGRMC1 enhances the activity of cytochrome P450 (Cyp) enzymes involved in steroid synthesis (Hughes et al., 2007; Rohe et al., 2009; Ahmed et al., 2012). For example, through its heme-binding site, PGRMC1 binds to and enhances the activity of Cyp51, an enzyme necessary for the conversion of lanosterol to cholesterol (Craven et al., 2007; Hughes et al., 2007). This is a key finding because cholesterol does not appear to be synthesized in the brain (Bjorkhem and Meaney, 2004). Similarly, PGRMC1 activates Cyp19 aromatase, an enzyme necessary for $\mathrm{E}_{2}$ synthesis (Ahmed et al., 2012), a hormone that acts in the AVPV to induce the LH surge (Petersen et al., 2003). It has not yet been determined whether PGRMC1 regulates the activity of other heme-dependent Cyp enzymes involved in $\mathrm{P}_{4}$ synthesis or its metabolism to other neuroactive progestins such as allopregnanolone. However, it seems likely considering that PGRMC1 regulates nearly all Cyp enzymes tested to date (Ahmed et al., 2012). Thus, PGRMC1 may indirectly amplify the preovulatory LH surge by enhancing activity of enzymes involved in neurosteroid synthesis and metabolism.

It is also possible that PGRMC1 mediates rapid inhibitory effects of $\mathrm{P}_{4}$ on $\mathrm{LH}$ release. Both PGRMC1 and SERBP1 are detected in nearly all GnRH neurons of embryonic explants, (Bashour and Wray, 2012). Similarly, PGRMC1 is found in immortalized GnRH neurons, GT1-7 cells (Krebs et al., 2000). As in non-neural cells (Peluso et al., 2002), $\mathrm{P}_{4}$ rapidly inhibits fluctuations in intracellular calcium levels in $\mathrm{GnRH}$ neurons through mechanisms that do not involve $\mathrm{GABA}_{A}$ receptors (Bashour and Wray, 2012) as have been described previously in embryonic sensory neurons (Viero et al., 2006). Rather, a putative PGRMC1 antagonist blocks the inhibitory effect of $\mathrm{P}_{4}$ and, consistent with evidence that PGRMC1 signals through PKG (Peluso and Pappalardo, 2004; Peluso et al., 2007), PKG inhibitors block $\mathrm{P}_{4}$ inhibition of calcium flux in explant $\mathrm{GnRH}$ neurons (Bashour and Wray, 2012). Thus, PGRMC1 may be important for turning off the $\mathrm{LH}$ surge or limiting it to one day of the cycle.

PGRMC1 is also interesting in the context of sexual differentiation of brain nuclei, particularly of preoptic area and hypothalamic nuclei that develop through sex-specific and $\mathrm{E}_{2}$ regulated apoptosis. Sexual differentiation of the AVPV occurs during the perinatal period when the developing testes, but not ovaries, are active. In the male AVPV, testosterone is aromatized to $\mathrm{E}_{2}$ and this hormone triggers apoptosis (Arai et al., 1996; Forger, 2009; Tsukahara, 2009) and defeminization of LH release mechanisms. Importantly, PGRMC1 prevents apoptosis in non-neural tissue (Peluso et al., 2009) and we recently found that PGRMC1 mRNA levels are lower in the neonatal AVPV of males than females (Figure 2). Moreover, the arylhydrocarbon receptor ligand, 2,3,7,8-tetrachlorodibenzo-p-dioxin, increases pgrmcl gene expression (Selmin et al., 1996) and developmental exposure to TCDD blocks defeminization of LH release (Mably et al., 1992). Thus, indirect evidence suggests that PGRMC1 may prevent cell death in the developing AVPV.

\section{FEMININE SEXUAL BEHAVIORS}

In addition to its effects on $\mathrm{GnRH}$ and $\mathrm{LH}$ release, $\mathrm{P}_{4}$ also rapidly enhances female mating behaviors through actions in brain regions that contain PGRMC1. Most of these brain regions 


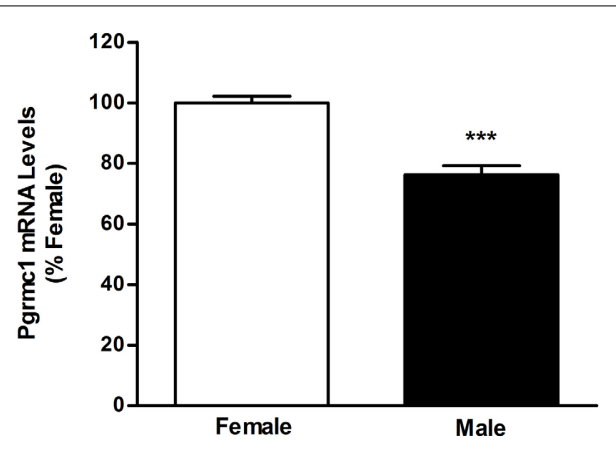

FIGURE 2 | Results of quantitative real-time polymerase chain reaction analyses measuring PGRMC1 mRNA in microdissections of postnatal day 2 female and male anteroventral periventricular nuclei.

*** Significantly different from female; $p<0.0001$.

also contain dopamine (DA) receptors and PGRMC1/sigma2R agonists increase DA release (Garcés-Ramírez et al., 2011). For example PGRMC1/sigma-2R mRNA levels are high in the medial preoptic area (Krebs et al., 2000; Intlekofer and Petersen, 2011), a region in which $\mathrm{P}_{4}$ increases DA release (Matuszewich et al., 2000). DA, in turn, acts through DA D2 receptors in the medial preoptic area to enhance feminine precopulatory behaviors (Graham and Pfaus, 2010). In addition, DA input into the medial preoptic area comes primarily from the zona incerta (Wagner et al., 1995), a region that contains high levels of PGRMC1, PGRMC2, and SERBP1mRNA. Levels are also high in the ventromedial hypothalamus (Krebs et al., 2000; Intlekofer and Petersen, 2011), a brain region in which both $\mathrm{P}_{4}$ (FlanaganCato, 2011) and DA D1 and D5 receptor agonists induce lordosis (Apostolakis et al., 1996). Finally, expression of PGRMC1 and binding partners is prominent in the ventral tegmental area (VTA) wherein $\mathrm{P}_{4}$ regulates the maintenance of lordosis through actions involving DA D1 and D5 receptors(Sumida et al., 2005).

As is the case with $\mathrm{GnRH} / \mathrm{LH}$ surge release, $\mathrm{PR}$ is required for the appearance of female mating behaviors, and both classical and ligand-independent activation of PR play a role (Mani and Blaustein, 2012). In fact, at least some of the DA-mediated effects on behavior require PR (Mani et al., 2009; Mani and Blaustein, 2012); however, that does not preclude the possibility that PGRMC1 also participates in the process. For example, sigma-2 ligands regulate DA transporter activity through a $\mathrm{Ca}^{2+} /$ calmodulin-dependent protein kinase II (CaMKII) transduction system (Weatherspoon and Werling, 1999). Likewise, $\mathrm{P}_{4}$ effects on female mating behavior involve rapid changes in CaMKII kinase activity in the ventromedial hypothalamus (Balasubramanian et al., 2008) through a mechanism upstream from DA receptor activation (Balasubramanian and Mani, 2009). Thus, it may be that $\mathrm{P}_{4}$ regulates DA release, reuptake and binding, as well as downstream signaling through a combination of classical and non-classical $\mathrm{P}_{4}$ receptors.

PGRMC1 may also affect DA signaling and female reproductive behaviors by altering NMDA-type glutamate receptor functions. As described above, the VTA is a site in which $\mathrm{P}_{4}$ facilitates female sexual behaviors (Debold and Malsbury, 1989). Therefore, it is intriguing that sigma-2 receptor agonists, which presumably bind PGRMC1 (Xu et al., 2011), potentiate NMDA-induced activity of DA neurons in the VTA (Gronier and Debonnel, 1999). Considering that DA signaling, but not PR action, in the VTA is required for lordosis (Frye and Vongher, 1999; Sumida et al., 2005), these findings support the idea that PGRMC1 plays a role. However, this is likely to be a complicated story because NMDA signaling in the VTA suppresses lordosis quotients under some circumstances (Frye et al., 2008). Thus, if PGRMC1 is part of the signaling mechanism that controls lordosis, it may be involved in turning off the behavior. Alternatively, it may be that responses to glutamate depend on the particular subregion of the VTA affected.

\section{OTHER POTENTIAL NEURAL FUNCTIONS OF PGRMC1}

Results of our neuroanatomical studies suggest that PGRMC1 may also mediate effects of $\mathrm{P}_{4}$ on non-reproductive functions. Two of the regions in which PGRMC1 was first detected are the supraoptic and paraventricular nuclei (Krebs et al., 2000; Meffre et al., 2005). These regions contain among the highest levels of PGRMC1, PGRMC2, and SERBP1 mRNA in the rat forebrain (Intlekofer and Petersen, 2011). PGRMC1 is also expressed in circumventricular organs, ependymal cells and meninges, and colocalizes with vasopressin in paraventricular and supraoptic nuclei; therefore, it has been proposed that PGRMC1 might be involved in water homeostasis in the brain (Meffre et al., 2005). Support for this idea comes from evidence that PGRMC1 expression increases in neurons and appears in astrocytes after traumatic brain injury that results in edema (Meffre et al., 2005). This finding has important clinical implications because $\mathrm{P}_{4}$ is now in clinical trials to evaluate its effectiveness on decreasing brain damage in stroke and traumatic brain injury (Stein, 2011). It remains to be determined whether $\mathrm{P}_{4}$ acts, at least in part, through PGRMC1 to exert its neuroprotective effects by controlling edema in the brain.

Finally, the piriform cortex is a part of the limbic system and both PGRMC1 and SERBP1 mRNA levels are very high in this region, while PR and $\mathrm{mPR}$ mRNAs are quite low or absent (Intlekofer and Petersen, 2011). This is not a well-studied brain structure from a neuroendocrine perspective, but the piriform cortex is central to the development and propagation of kindled seizures (Wahnschaffe et al., 1993; Loscher et al., 1995). Although no changes in kindled seizure threshold are observed during the estrous cycle of rats (Wahnschaffe and Loscher, 1992), many women with epilepsy experience seizures clustered around the time of the menstrual cycle when $\mathrm{P}_{4}$ levels are low (termed catamenial epilepsy) (Duncan et al., 1993; Herzog et al., 2004; Gilad et al., 2008; Reddy, 2009). $\mathrm{P}_{4}$ can significantly reduce the frequency of seizures in women with this disease (Reddy, 2009; Motta et al., 2013). Further studies are required to determine whether PGRMC1 plays a role in catamenial epilepsy and whether PGRMC1/sigma-2 ligands would be effective in treating the disease without the side effects of progestins.

\section{SUMMARY}

A large body of literature catalogues the many neural actions of $\mathrm{PR}$ accomplished through gene regulation or rapid regulation of intracellular signaling. In contrast, there is relatively little work on the role of PGRMC1 or other non-classical $\mathrm{P}_{4}$ signaling 
molecules in the brain. Based on our neuroanatomical findings that PGRMC1, PGRMC2, and SERBP1 are found in brain regions wherein $\mathrm{P}_{4}$ exerts rapid effects, it seems likely that these molecules are involved in diverse functions. These functions include the control of $\mathrm{GnRH} / \mathrm{LH}$ release, feminine mating behaviors, fluid balance, and neuroprotection and seizure activity. The extensive

\section{REFERENCES}

Ahmed, I. S. A., Chamberlain, C., and Craven, R. J. (2012). S2rpgrmc1: the cytochrome-related sigma-2 receptor that regulates lipid and drug metabolism and hormone signaling. Expert Opin. Drug Metab. Toxicol. 8, 361-370. doi: $10.1517 / 17425255.2012 .658367$

Albrecht, C., Huck, V., Wehling, M., and Wendler, A. (2012). In vitro inhibition of skov-3 cell migration as a distinctive feature of progesterone receptor membrane component type 2 versus type 1 . Steroids 77, 1543-1550. doi: 10.1016/j.steroids.2012.09.006

Apostolakis, E. M., Garai, J., Fox, C., Smith, C. L., Watson, S. J., Clark, J. H., et al. (1996). Dopaminergic regulation of progesterone receptors: brain $\mathrm{d} 5$ dopamine receptors mediate induction of lordosis by $\mathrm{d} 1$ like agonists in rats. J. Neurosci. 16, 4823-4834.

Arai, Y., Sekine, Y., and Murakami, S. (1996). Estrogen and apoptosis in the developing sexually dimorphic preoptic area in female rats. Neurosci. Res. 25, 403-407. doi: 10.1016/0168-0102(96)01070-X

Ashley, R. L., Clay, C. M., Farmerie, T. A., Niswender, G. D., and Nett, T. M. (2006). Cloning and characterization of an ovine intracellular seven transmembrane receptor for progesterone that mediates calcium mobilization. Endocrinology 147, 4151-4159. doi: 10.1210/en.2006-0002

Balasubramanian, B., and Mani, S. K. (2009). Dopamine agonist signalling in the hypothalamus of female rats is independent of calcium-dependent kinases. J. Neuroendocrinol. 21, 954-960. doi: $\quad 10.1111 / j .1365-2826.2009$. 01917.x

Balasubramanian, B., Portillo, W., Reyna, A., Chen, J. Z., Moore, A. N., Dash, P. K., et al. (2008). Nonclassical mechanisms of progesterone action in the brain: Ii. Role of calmodulindependent protein kinase ii in progesterone-mediated signaling in the hypothalamus of female rats. Endocrinology 149, 5518-5526. doi: 10.1111/j.1365-2826.2009.01917.x
Bali, N., Arimoto, J. M., Iwata, N., Lin, S. W., Zhao, L., Brinton, R. D., et al. (2012). Differential responses of progesterone receptor membrane component-1 (pgrmc1) and the classical progesterone receptor (pgr) to $17 \beta$-estradiol and progesterone in hippocampal subregions that support synaptic remodeling and neurogenesis. Endocrinology 153, 759-769. doi: 10.1210/en.2011-1699

Bashour, N. M., and Wray, S. (2012). Progesterone directly and rapidly inhibits gnrh neuronal activity via progesterone receptor membrane component 1. Endocrinology 153, 4457-4469. doi: 10.1210/en.20121122

Baudry, M., Bi, X., and Aguirre, C. (2013). Progesterone-estrogen interactions in synaptic plasticity and neuroprotection. Neuroscience 239, 280-294. doi: 10.1016/j. neuroscience.2012.10.051

Bjorkhem, I., and Meaney, S. (2004). Brain cholesterol: long secret life behind a barrier. Arterioscler. Thromb. Vasc. Biol. 24, 806-815. doi: 10.1161/01.ATV.0000120374. $59826.1 \mathrm{~b}$

Cahill, M. A. (2007). Progesterone receptor membrane component 1 : an integrative review. J Steroid Biochem. Mol. Biol. 105, 16-36. doi: 10.1016/j.jsbmb.2007.02.002

Chabbert-Buffeta, N., Skinner, D. C., Caraty, A., and Bouchard, P. (2000). Neuroendocrine effects of progesterone. Steroids 65, 613-620. doi: 10.1016/S0039-128X(00)00187-2

Chappell, P. E., Schneider, J. S., Kim, P., Xu, M., Lydon, J. P., O'malley, B. W., et al. (1999). Absence of gonadotropin surges and gonadotropin-releasing hormone self-priming in ovariectomized (ovx), estrogen (e2)-treated, progesterone receptor knockout (prko) mice. Endocrinology 140, 3653-3658. doi: 10.1210/en. 140.8 .3653

Chappell, P. E., and Levine, J. E. (2000). Stimulation of gonadotropinreleasing hormone surges by estrogen. I. Role of hypothalamic progesterone receptors. Endocrinology 141, 1477-1485. doi: 10.1210/en.141.4.1477

overlap in patterns and levels of expression suggest that PGRMC1 and PR signaling pathways regulate the same cellular functions, but probably through different mechanisms. Considering the importance of these functions in physiology and disease, further study of PGRMC1, PGRMC2, and SERBP1 in the nervous system is warranted.

Chappell, P. E., Lydon, J. P., Conneely, O. M., O'malley, B. W., and Levine, J. E. (1997). Endocrine defects in mice carrying a null mutation for the progesterone receptor gene. Endocrinology 138, 4147-4152. doi: 10.1210/en.138.10.4147

Craven, R. J., Mallory, J. C., and Hand, R. A. (2007). Regulation of iron homeostasis mediated by the heme-binding protein dap1 (damage resistance protein 1) via the p450 protein erg11/cyp51. Journal Biol. Chem. 282, 36543-36551. doi: 10.1074/jbc.M706770200

Debold, J. F., and Malsbury, C. W. (1989). Facilitation of sexual receptivity by hypothalamic and midbrain implants of progesterone in female hamsters. Physiol. Behav. 46, 655-660. doi: 10.1016/00319384(89)90347-8

Duncan, S., Read, C. L., and Brodie, M. J. (1993). How common is catamenial epilepsy? Epilepsia 34, 827-831. doi: 10.1111/j.15281157.1993.tb02097.x

Falkenstein, E., Meyer, C., Eisen, C., Scriba, P. C., and Wehling, M. (1996). Full-length cdna sequence of a progesterone membrane-binding protein from porcine vascular smooth muscle cells. Biochem. Biophys. Res. Commun. 229, 86-89. doi: 10.1006/bbrc.1996.1761

Flanagan-Cato, L. M. (2011). Sex differences in the neural circuit that mediates female sexual receptivity. Front. Neuroendocrinol. 32, 124-136. doi: 10.1016/j.yfrne.2011. 02.008

Forger, N. G. (2009). Control of cell number in the sexually dimorphic brain and spinal cord. J. Neuroendocrinol. 21, 393-399. doi: $\quad 10.1111 /$ j.1365-2826.2009. 01825. $\mathrm{x}$

Frye, C. A., Marrone, J., and Walf, A. (2008). Effects of manipulating progesterone and nmda receptors in the ventral tegmental area for lordosis of hamsters and rats. Psychopharmacology 200, 71-80. doi: 10.1007/s00213-008-1143-6

Frye, C. A., and Vongher, J. M. (1999). Gabaa, d1, and d5, but not progestin receptor, antagonist and antisense oligonucleotide infusions to the ventral tegmental area of cycling rats and hamsters attenuate lordosis. Behav. Brain Res. 103, 23-34. doi: 10.1016/S0166-4328(99)00020-0

Garcés-Ramírez, L., Green, J. L., Hiranita, T., Kopajtic, T. A., Mereu, M., Thomas, A. M., et al. (2011). Sigma receptor agonists: receptor binding and effects on mesolimbic dopamine neurotransmission assessed by microdialysis. Biol. Psychiatry 69, 208-217. doi: 10.1016/j.biopsych.2010.07.026

Giatti, S., Boraso, M., Melcangi, R. C., and Viviani, B. (2012). Neuroactive steroids, their metabolites, and neuroinflammation. J. Mol. Endocrinol. 49, R125-R134. doi: 10.1530/JME12-0127

Gilad, R., Sadeh, M., Rapoport, A., Dabby, R., and Lampl, Y. (2008). Lamotrigine and catamenial epilepsy. Seizure 17, 531-534. doi: 10.1016/j.seizure.2008.02.001

Graham, M. D., and Pfaus, J. G. (2010). Differential regulation of female sexual behaviour by dopamine agonists in the medial preoptic area. Pharmacol. Biochem. Behav. 97, 284-292. doi: 10.1016/j.pbb.2010.08.012

Gronier, B., and Debonnel, G. (1999). Involvement of sigma receptors in the modulation of the glutamatergic/nmda neurotransmission in the dopaminergic systems. Eur. J. Pharmacol. 368, 183-196. doi: 10.1016/S0014-2999(99)00025-4

Herzog, A. G., Harden, C. L., Liporace, J., Pennell, P., Schomer, D. L., Sperling, M., et al. (2004). Frequency of catamenial seizure exacerbation in women with localization-related epilepsy. Ann. Neurol. 56, 431-434. doi: 10.1002/ana.20214

Hughes, A. L., Powell, D. W., Bard, M., Eckstein, J., Barbuch, R., Link, A. J., et al. (2007). Dap1/pgrmcl binds and regulates cytochrome p450 enzymes. Cell Metab. 5, 143-149. doi: 10.1016/j.cmet.2006.12.009

Intlekofer, K. A., and Petersen, S. L. (2011). Distribution of mrnas encoding classical progestin receptor, progesterone membrane components 1 and 2, serpine mrna binding protein 1 , and progestin and adipoq receptor family 
members 7 and 8 in rat forebrain. Neuroscience 172, 55-65. doi: 10.1016/j.neuroscience.2010.10.051

Karteris, E., Zervou, S., Pang, Y., Dong, J., Hillhouse, E. W., Randeva, H. S., et al. (2006). Progesterone signaling in human myometrium through two novel membrane g proteincoupled receptors: potential role in functional progesterone withdrawal at term. Mol. Endocrinol. 20, 1519-1534. doi: 10.1210/me.20050243

Kimura, I., Konishi, M., Miyake, A., Fujimoto, M., and Itoh, N. (2006). Neudesin, a secreted factor, promotes neural cell proliferation and neuronal differentiation in mouse neural precursor cells. J. Neurosci. Res. 83, 1415-1424. doi: 10.1002/jnr.20849

Kimura, I., Yoshioka, M., Konishi, M., Miyake, A., and Itoh, N. (2005). Neudesin, a novel secreted protein with a unique primary structure and neurotrophic activity. J. Neurosci. Res. 79, 287-294. doi: 10.1002/jnr.20356

Kimura, I., Nakayama, Y., Yamauchi, H., Konishi, M., Miyake, A., Mori, M., et al. (2008). Neurotrophic activity of neudesin, a novel extracellular heme-binding protein, is dependent on the binding of heme to its cytochrome b5-like heme/steroid-binding domain. J. Biol. Chem. 283, 4323-4331. doi: 10.1074/jbc.M706679200

Kimura, I., Nakayama, Y., Konishi, M., Kobayashi, T., Mori, M., Ito, M., et al. (2010). Neuferricin, a novel extracellular heme-binding protein, promotes neurogenesis. J. Neurochem. 112, 1156-1167. doi: 10.1111/j.1471-4159.2009.06522.x

Kimura, I., Nakayama, Y., Konishi, M., Terasawa, K., Ohta, M., Itoh, N., et al. (2012). Functions of mapr (membrane-associated progesterone receptor) family members as heme/steroid-binding proteins. Curr. Protein Pept. Sci. 13, 687-696.

Kowalik, M. K., and Kotwica, J. (2008). Progesterone receptor membrane component 1 (pgrmcl) gene expression in corpus luteum during the estrous cycle in cows. Reprod. Biol. 8, 291-297. doi: 10.1016/S1642-431X(12)60019-9

Krebs, C. J., Jarvis, E. D., Chan, J., Lydon, J. P., Ogawa, S., and Pfaff, D. W. (2000). A membrane-associated progesterone-binding protein, 25$\mathrm{dx}$, is regulated by progesterone in brain regions invovled in female reproductive behaviors. Proc. Natl. Acad. Sci. U.S.A. 97, 12816-12821. doi: $10.1073 /$ pnas.97.23.12816
Krietsch, T., Fernandes, M. S., Kero, J., Losel, R., Heyens, M., Lam, E. W., et al. (2006). Human homologs of the putative g proteincoupled membrane progestin receptors (mpralpha, beta, and gamma) localize to the endoplasmic reticulum and are not activated by progesterone. Mol. Endocrinol. 20, 3146-3164. doi: 10.1210/me.2006-0129

Lai, J.-N., Wang, O. Y.-H., Lin, V. H.-C., Liao, C.-F., Tarng, D.-C., and Chien, E. J. (2012). The non-genomic rapid acidification in peripheral $t$ cells by progesterone depends on intracellular calcium increase and not on nat/h+-exchange inhibition. Steroids 77, 1017-1024. doi: 10.1016/j.steroids.2012.03.004

Levine, J. E. (1997). New concepts of the neuroendocrine regulation of gonadotropin surges in rats. Biol. Reprod. 56, 293-302. doi: 10.1095/biolreprod56.2.293

Loscher, W., Ebert, U., Wahnschaffe, U., and Rundfeldt, C. (1995) Susceptibility of different cell layers of the anterior and posterior part of the piriform cortex to electrical stimulation and kindling: comparison with the basolateral amygdala and "area tempestas." Neuroscience 66, 265-276. doi: 10.1016/0306-4522(94)00614-B

Losel, R., Breiter, S., Seyfert, M., Wehling, M., and Falkenstein, E. (2005). Classic and non-classic progesterone receptors are both expressed in human spermatozoa. Horm. Metab. Res 37, 10-14. doi: 10.1055/s-2005-861023

Mably, T. A., Moore, R. W., Goy, R. W., and Peterson, R. E. (1992). In utero and lactational exposure of male rats to 2,3,7,8-tetrachlorodibenzop-dioxin. 2. Effects on sexual behavior and the regulation of luteinizing hormone secretion in adulthood. Toxicol. Appl. Pharmacol. 114, 108-117. doi: 10.1016/0041-008X(92)90102-X

Mani, S. K., and Blaustein, J. D. (2012). Neural progestin receptors and female sexual behavior. Neuroendocrinology 96, 152-161. doi: 10.1159/000338668

Mani, S. K., Portillo, W., and Reyna, A. (2009). Steroid hormone action in the brain: cross-talk between signalling pathways. J. Neuroendocrinol. 21, 243-247. doi: 10.1111/j.13652826.2009.01844.x

Matuszewich, L., Lorrain, D. S., and Hull, E. M. (2000). Dopamine release in the medial preoptic area of female rats in response to hormonal manipulation and sexual activity.
Behav. Neurosci. 114, 772-782. doi 10.1037/0735-7044.114.4.772

Meffre, D., Delespierre, B., Gouezou, M., Leclerc, P., Vinson, G. P., Schumacher, M., et al. (2005). The membrane-associated progesterone-binding protein 25- $\mathrm{dx}$ is expressed in brain regions involved in water homeostasis and is up-regulated after traumatic brain injury. J. Neurochem. 93, 1314-1326. doi: 10.1111/j.14714159.2005.03127.x

Meyer, C., Schmid, R., Scriba, P. C., and Wehling, M. (1996). Purification and partial sequencing of highaffinity progesterone-binding site(s) from porcine liver membranes. Eur. J. Biochem. 239, 726-731. doi: 10.1111/j.1432-1033.1996.0726u.x

Micevych, P., and Sinchak, K. (2008) Estradiol regulation of progesterone synthesis in the brain. Mol. Cell. Endocrinol. 290, 44-50. doi: 10.1016/j.mce.2008.04.016

Micevych, P. E., and Sinchak, K. (2011) The neurosteroid progesterone underlies estrogen positive feedback of the lh surge. Front. Endocrinol. 2:90. doi: 10.3389/fendo.2011.00090

Min, L., Strushkevich, N. V., Harnastai, I. N., Iwamoto, H., Gilep, A. A., Takemori, H., et al. (2005). Molecular identification of adrenal inner zone antigen as a hemebinding protein. FEBS J. 272, 5832-5843. doi: 10.1111/j.1742 4658.2005.04977.x

Motta, E., Golba, A., Ostrowska, Z. Steposz, A., Huc, M., Kotas-Rusnak, J., et al. (2013). Progesterone therapy in women with epilepsy. Pharmacol. Rep. 65, 89-98.

Moussatche, P., and Lyons, T. J. (2012). Non-genomic progesterone signalling and its non-canonical receptor. Biochem. Soc. Trans. 40, 200-204. doi: 10.1042/BST20110638

Nilsen, J., and Brinton, R. D. (2003) Divergent impact of progesterone and medroxyprogesterone acetate (provera) on nuclear mitogen-activated protein kinase signaling. Proc. Natl. Acad. Sci. U.S.A. 100, 10506-10511. doi: 10.1073/pnas. 1334098100

Pang, Y., Dong, J., and Thomas, P. (2013). Characterization, neurosteroid binding and brain distribution of human membrane progesterone receptors delta and epsilon (mprdelta and mprepsilon) and mprdelta involvement in neurosteroid inhibition of apoptosis. Endocrinology 154, 283-295. doi: 10.1210/en.2012-1772

Peluso, J. J. (2011). Progesterone signaling mediated through progesterone receptor membrane component-1 in ovarian cells with special emphasis on ovarian cancer. Steroids 76, 903-909. doi: 10.1016/j.steroids. 2011.02.011

Peluso, J. J., Fernandez, G., Pappalardo, A., and White, B. A. (2002). Membrane-initiated events account for progesterone's ability to regulate intracellular free calcium levels and inhibit rat granulosa cell mitosis. Biol. Reprod. 67, 379-385. doi: 10.1095/biolreprod67.2.379

Peluso, J. J., Liu, X., Gawkowska, A., and Johnston-Macananny, E. (2009). Progesterone activates a progesterone receptor membrane component 1-dependent mechanism that promotes human granulosa/luteal cell survival but not progesterone secretion. J. Clin. Endocrinol. Metab. 94, 2644-2649. doi: 10.1210/jc.2009-0147

Peluso, J. J., Liu, X., and Romak, J. (2007). Progesterone maintains basal intracellular adenosine triphosphate levels and viability of spontaneously immortalized granulosa cells by promoting an interaction between 1413-3sigma and atp synthase beta/precursor through a protein kinase g-dependent mechanism. Endocrinology 148, 2037-2044. doi: 10.1210/en.2006-1603

Peluso, J. J., Lodde, V., and Liu, X (2012). Progesterone regulation of progesterone receptor membrane component 1 (pgrmc1) sumoylation and transcriptional activity in spontaneously immortalized granulosa cells. Endocrinology 153, 3929-3939. doi: 10.1210/en.20112096

Peluso, J. J., and Pappalardo, A. (2004). Progesterone regulates granulosa cell viability through a protein kinase g-dependent mechanism that may involve 14-13-3sigma. Biol. Reprod. 71, 1870-1878. doi: 10.1095/biolreprod.104.031716

Peluso, J. J., Pappalardo, A., Losel, R., and Wehling, M. (2006). Progesterone membrane receptor component 1 expression in the immature rat ovary and its role in mediating progesterone's antiapoptotic action. Endocrinology 147, 3133-3140. doi: 10.1210/en.2006-0114

Peluso, J. J., Romak, J., and Liu, X. (2008). Progesterone receptor membrane component-1 (pgrmc1) is the mediator of progesterone's antiapoptotic action in spontaneously immortalized granulosa cells as revealed by pgrmcl small interfering ribonucleic acid treatment and functional 
analysis of pgrmcl mutations. Endocrinology 149, 534-543. doi: 10.1210/en.2007-1050

Peluso, J. J., Yuan, A., Liu, X., and Lodde, V. (2013). Plasminogen activator inhibitor 1 rna-binding protein interacts with progesterone receptor membrane component 1 to regulate progesterone's ability to maintain the viability of spontaneously immortalized granulosa cells and rat granulosa cells. Biol. Reprod. 88, 20, 21-10. doi: 10.1095/biolreprod.112.103036

Petersen, S. L., Intlekofer, K. A., MouraConlon, P. J., Brewer, D. N., Del Pino Sans, J., and Lopez, J. A. (2013). Non-classical progesterone signalling molecules in the nervous system. J. Neuroendocrinol. doi: 10.1111/jne.12060. [Epub ahead of print].

Petersen, S. L., Ottem, E. N., and Carpenter, C. D. (2003). Direct and indirect regulation of gonadotropin-releasing hormone neurons by estradiol. Biol. Reprod. 69, 1771-1778. doi: 10.1095/ biolreprod.103.019745

Peterson, T. C., Anderson, G. D., Kantor, E. D., and Hoane, M. R. (2012). A comparison of the effects of nicotinamide and progesterone on functional recovery of cognitive behavior following cortical contusion injury in the rat. J. Neurotrauma 29, 2823-2830. doi: 10.1089/neu.2012.2471

Raza, F. S., Takemori, H., Tojo, H., Okamoto, M., and Vinson, G. P. (2001). Identification of the rat adrenal zona fasciculata/reticularis specific protein, inner zone antigen (izag), as the putative membrane progesterone receptor. Eur. J. Biochem. 268, 2141-2147. doi: 10.1046/j.1432-1327.2001.02096.x

Reddy, D. S. (2009). The role of neurosteroids in the pathophysiology and treatment of catamenial epilepsy. Epilepsy Res. 85, 1-30. doi: 10.1016/j.eplepsyres.2009.02.017

Rohe, H. J., Ahmed, I. S., Twist, K. E., and Craven, R. J. (2009). Pgrmcl (progesterone receptor membrane component 1): a targetable protein with multiple functions in steroid signaling, p450 activation and drug binding. Pharmacol. Ther. 121, 14-19. doi: 10.1016/j.pharmthera. 2008.09.006

Sanchez, A. M., Flamini, M. I., Genazzani, A. R., and Simoncini, T. (2013). Effects of progesterone and medroxyprogesterone on actin remodeling and neuronal spine formation. Mol. Endocrinol. 27, 693-702. doi: 10.1210/me.2012-1278

Selmin, O., Lucier, G. W., Clark, G. C., Tritscher, A. M., Vanden Heuvel, J. P., Gastel, J. A., et al. (1996). Isolation and characterization of a novel gene induced by $2,3,7,8$ tetrachlorodibenzo-p-dioxin in rat liver. Carcinogenesis 17, 2609-2615. doi: 10.1093/carcin/17.12.2609

Shughrue, P. J., Lane, M. V., and Merchenthaler, I. (1997). Regulation of progesterone receptor messenger ribonucleic acid in the rat medial preoptic nucleus by estrogenic and antiestrogenic compounds: an in situ hybridization study. Endocrinology 138, 5476-5484. doi: 10.1210/en.138.12. 5476

Simerly, R. B., Carr, A. M., Zee, M. C., and Lorang, D. (1996). Ovarian steroid regulation of estrogen and progesterone receptor messenger ribonucleic acid in the anteroventral periventricular nucleus of the rat. J. Neuroendocrinol. 8, 45-56. doi: $\quad 10.1111 /$ j.1365-2826.1996. tb00685.x

Smith, J. L., Kupchak, B. R., Garitaonandia, I., Hoang, L. K., Maina, A. S., Regalla, L. M., et al. (2008). Heterologous expression of human mpralpha, mprbeta and mprgamma in yeast confirms their ability to function as membrane progesterone receptors. Steroids 73, 1160-1173. doi: 10.1016/j.steroids.2008.05.003

Stein, D. G. (2011). Is progesterone a worthy candidate as a novel therapy for traumatic brain injury? Dialogues Clin. Neurosci. 13, 352-359.

Sumida, K., Walf, A. A., and Frye, C. A. (2005). Progestin-facilitated lordosis of hamsters may involve dopamine-like type 1 receptors in the ventral tegmental area. Behav. Brain Res. 161, 1-7. doi: 10.1016/j.bbr.2005.02.013

Thomas, P., and Pang, Y. (2012). Membrane progesterone receptors: evidence for neuroprotective, neurosteroid signaling and neuroendocrine functions in neuronal cells. Neuroendocrinology 96, 162-171. doi: 10.1159/000339822

Tsukahara, S. (2009). Sex differences and the roles of sex steroids in apoptosis of sexually dimorphic nuclei of the preoptic area in postnatal rats. J. Neuroendocrinol. 21, 370-376. doi: 10.1111/j.13652826.2009.01855.x
Viero, C., Mechaly, I., Aptel, H., Puech, S., Valmier, J., Bancel, F., et al. (2006). Rapid inhibition of ca2+ influx by neurosteroids in murine embryonic sensory neurones. Cell Calcium 40, 383-391. doi: 10.1016/j.ceca.2006.04.007

Villa, N. Y., Kupchak, B. R., Garitaonandia, I., Smith, J. L., Alonso, E., Alford, C., et al. (2009). Sphingolipids function as downstream effectors of a fungal paqr. Mol. Pharmacol. 75, 866-875. doi 10.1124/mol.108.049809

Vilner, B. J., and Bowen, W. D. (1993). Sigma receptor-active neuroleptics are cytotoxic to 66 glioma cells in culture. Eur. J. Pharmacol. 244, 199-201. doi: 10.1016/09224106(93)90029-9

Vilner, B. J., and Bowen, W. D. (2000). Modulation of cellular calcium by sigma-2 receptors: release from intracellular stores in human sk-n-sh neuroblastoma cells. J. Pharmacol. Exp. Ther. 292, 900-911.

Vilner, B. J., De Costa, B. R., and Bowen, W. D. (1995). Cytotoxic effects of sigma ligands: sigma receptor-mediated alterations in cellular morphology and viability. J. Neurosci. 15, 117-134.

Wagner, C. K., Eaton, M. J., Moore, K. E., and Lookingland, K. J. (1995). Efferent projections from the region of the medial zona incerta containing a13 dopaminergic neurons: a pha-l anterograde tracttracing study in the rat. Brain Res. 677, 229-237. doi: 10.1016/00068993(95)00128-D

Wahnschaffe, U., Ebert, U., and Loscher, W. (1993). The effects of lesions of the posterior piriform cortex on amygdala kindling in the rat. Brain Res. 615, 295-303. doi: 10.1016/0006-8993(93)90041-K

Wahnschaffe, U., and Loscher, W. (1992). Lack of changes in seizure susceptibility during the estrous cycle in kindled rats. Epilepsy Res. 13, 199-204. doi: 10.1016/0920 1211(92)90053-V

Watson, S., Gallagher, P., Porter, R. J., Smith, M. S., Herron, L. J., Bulmer, S., et al. (2012). A randomized trial to examine the effect of mifepristone on neuropsychological performance and mood in patients with bipolar depression. Biol. Psychiatry 72, 943-949. doi: 10.1016/j.biopsych. 2012.05.029

Weatherspoon, J. K., and Werling, L. L. (1999). Modulation of amphetamine-stimulated [3h] dopamine release from rat pheochromocytoma (pc12) cells by 5 type 2 receptors. J. Pharmacol. Exp. Ther. 289, 278-284.

Wendler, A., and Wehling, M. (2013). Pgrmc2, a yet uncharacterized protein with potential as tumor suppressor, migration inhibitor, and regulator of cytochrome p450 enzyme activity. Steroids 78, 555-558. doi: 10.1016/j.steroids. 2012.12.002

$\mathrm{Xu}$, J., Zeng, C., Chu, W., Pan, F., Rothfuss, J. M., Zhang, F., et al. (2011). Identification of the pgrmc1 protein complex as the putative sigma-2 receptor binding site. Nat. Commun. 2, 380. doi: 10.1038/ncomms1386

Zhang, L., Kanda, Y., Roberts, D. J., Ecker, J. L., Losel, R., Wehling, M., et al. (2008). Expression of progesterone receptor membrane component 1 and its partner serpine 1 mrna binding protein in uterine and placental tissues of the mouse and human. Mol. Cell. Endocrinol. 287, 81-89. doi: 10.1016/j.mce.2008.02.012

Conflict of Interest Statement: The authors declare that the research was conducted in the absence of any commercial or financial relationships that could be construed as a potential conflict of interest.

Received: 28 May 2013; paper pending published: 21 June 2013; accepted: 24 August 2013; published online: 19 September 2013.

Citation: Petersen SL, Intlekofer KA, Moura-Conlon PJ, Brewer DN, Del Pino Sans J and Lopez JA (2013) Novel progesterone receptors: neural localization and possible functions. Front. Neurosci. 7:164. doi: 10.3389/fnins.2013.00164 This article was submitted to Neuroendocrine Science, a section of the journal Frontiers in Neuroscience. Copyright (c) 2013 Petersen, Intlekofer, Moura-Conlon, Brewer, Del Pino Sans and Lopez. This is an open-access article distributed under the terms of the Creative Commons Attribution License (CC BY). The use, distribution or reproduction in other forums is permitted, provided the original author(s) or licensor are credited and that the original publication in this journal is cited, in accordance with accepted academic practice. No use, distribution or reproduction is permitted which does not comply with these terms. 